Egypt. Poult. Sci. Vol. (41) (II): (249-263)(2021)

Egyptian Poultry Science Journal

http://www.epsj.journals.ekb.eg/

ISSN: 1110-5623 (Print) - 2090-0570 (Online)

\title{
EFFECTS OF DIETARY FISH OIL SUPPLEMENTATIONON PERFORMANCE, GUT MORPHOLOGY, PROTOZOAN LOAD AND HISTOPATHOLOGICAL INDICES OF BROILER CHICKENS
}

\author{
A. F. Agboola*; B. R. O. Omidiwura; E. I. Okiwelu; and S. Agbuza \\ Dep. of Anim.Sci., Uni. of Ibadan, Ibadan, Oyo state, Nigeria
}

Corresponding author: A. F. Agboola Email:adebisi.agboola@ gmail.com, Received: 08/03/2021 Accepted: 20/04/2021

ABSTRACT:The effect of dietary supplementation of fish oil on performance and gut health of broiler chickens was examined. Two hundred one-day old broiler chicks were randomly allotted to 4 treatments with 5 replicates of 10 birds each in a completely randomized design. Diet 1: basal diet without feed additives. Diet 2: basal + coccidiostat $(0.06 \%)$, Diet 3: basal $+2.5 \%$ fish oil and Diet 4 : basal $+5 \%$ fish oil. Performance indices were measured. On day 56, distal ileum of two birds per replicate were severed for gut morphological measurements and digesta samples were collected for protozoan load counts. About $5 \mathrm{~cm}$ of the jejunum, ileum and caeca were excised for histological examinations.

The results showed that dietary fish oil supplementation did not have significant effect on the performance of broiler chickens at the starter phase. However, there was a negative effect of the fish oil in the final weight and feed conversion ratio of birds at the finisher phase. Final weights of birds that received the basal diet $(1736 \mathrm{~g} / \mathrm{b})$ were significantly higher $(\mathrm{P}<0.05)$ than those placed on 5\% fish oil supplemented diet $(1556.3 \mathrm{~g} / \mathrm{b})$. Crypt depth and villus height of birds fed with $5 \%$ fish oil supplemented diet were significantly higher $(\mathrm{P}<0.05)$ than those on the other diets. Birds on the control diet had numerous coccidia while fewer coccidia were observed in birds fed coccidiostat, $2.5 \%$ and $5 \%$ fish oil diets. Photomicrographs of the jejunum, ileum and caeca of birds fed the basal diet showed numerous developing stages of coccidia in the degenerated enterocytes, loss of villi and cryptal degeneration. Those on coccidiostat diet showed fusion, atrophy of villi and necrosis of mucous cells. However, in birds fed $2.5 \%$ and $5 \%$ fish oil supplemented diets; mild expansion of lamina propria and normal mucosa with no observable lesions were recorded.

In conclusion, dietary supplementation of 2.5 or $5.0 \%$ fish oil resulted in adverse effect on broilers performance (body weight and FCR) accompanied with slight improvement of gut health.

Keywords: Broilers, Fish oil, Growth response, Microbiome, Histology 


\section{A. F. Agboola et al.}

\section{INTRODUCTION}

The poultry sector constitutes more than $57 \%$ of the total livestock production in Nigeria (Alabi and Osifo, 2004). However, in recent years, the growth has retrogressed because of the challenges of many diseases faced by the poultry industry especially coccidiosis which is considered the most economic important parasitic disease affecting poultry production. Coccidiosis is caused by protozoan parasites of the genus Eimeria which are highly proliferative organisms by inhabiting and multiplying in the intestinal tract of poultry birds. The disease causes high production losses and high morbidity (Shirley et al., 2005; Blake et al., 2020). Coccidiosis results in gastro-intestinal tract (GIT) lesions which reduces nutrient absorption and decreases performance. In more severe cases, mortality can occur. Eimeria species are considered to be monoxenous because the life cycle is completed within a single host and the most economically important species are E. tenella, E. acervulina and E. maxima (Yun et al., 2000). The main problem with Eimeria infections is that they are caused by more than one species that attack different regions of the intestine. The protozoan parasites invade the intestinal wall and starts to reproduce, damaging gut tissue, causing poor digestion and nutrient absorption. Depending on the Eimeria species involved, this takes place in different parts of the intestine, in all cases, causing economic loss to poultry farmers.

The vast use of sulfonamides or synthetic chemical compounds for the treatment of coccidiosis in poultry has resulted in the emergence of drug-resistant strains and residues in poultry meat posing serious problems to poultry meat consumers (Blake and Tomley, 2014). However, incorporation of fish oil, which contains omega- 3 fatty acids in the diet of broilers, has been reported to improve birds' performance (Fritsche and Cassity, 1992; Allen et al., 1996; Allen et al., 1998). Fish oil contains unsaturated fatty acids with long omega-3 chains (n-3 PUFA), eicosapentaenoic acid (EPA 20:5, n-3) and docosahexaenoic acid (DHA 22:6, n3 ) that improve health-related factors in humans and animals. One possible mode of action is the infiltration of tissues of the parasite by omega-3 making the tissues become more susceptible to oxidative attack by phagocytic cells. Studies indicate that dietary fish oil decreases the level of total cholesterol, low-density lipoprotein and triglycerides (Crespo and Esteve-Garcia, 2001; Agboola et al., 2016). Its effect on parasite reduction, though has been reported in few studies, has not been fully elucidated. Hence, the need for study on broiler chickens. It was therefore the objective of this study to determine the effect of dietary fish oil supplementation on the performance, gut morphology, protozoan load and histopathology of broiler chickens.

\section{MATERIALS AND METHODS}

\section{Experimental site}

This experiment was carried out at the Poultry Unit of the Teaching and Research Farm, University of Ibadan, Ibadan, Nigeria.

\section{Experimental diets and management of birds}

Two hundred (200) one-day old unsexed Marshall broiler chicks used for this experiment were obtained from a reputable local commercial hatchery in Ibadan. The birds were tagged, weighed and randomly allotted to 4 dietary treatments sorted by body weight in a completely randomized design. Each diet had 5 replicates of 10 birds each. Diet 1 was the basal diet with no inclusion of 
Broilers, Fish oil, Growth response, Microbiome, Histology

any supplement (control diet). Diet 2 was basal diet $+0.06 \%$ commercial coccidiostat; diet 3 was basal diet $+2.5 \%$ fish oil while diet 4 contained basal diet + $5.0 \%$ fish oil. The gross compositions of the experimental broiler starter and finisher diets were as shown in Tables 1 and 2. The experimental diets and fresh water were provided ad libitum during the study period that lasted 56 days.

\section{Data collection}

\section{Performance parameters}

Feed intake was calculated as difference between amounts given and left over. The birds were weighed at the end of the starter and finisher phases and values were used to calculate body weight gain and feed conversion ratio.

\section{Protozoa load determination}

On day 56, two birds from each replicate were selected, weighed and slaughtered and the digestive tracts were carefully excised. The terminal two thirds of the section between Meckel's diverticulum and $2 \mathrm{~cm}$ anterior to the ileo-caecocolonic junction were severed. The contents were flushed and pooled according to replicates. The samples were then placed immediately in ice and stored until further analysis.

Intestinal morphometric measurements About $3 \mathrm{~cm}$ lengths of ileal section were cut from two birds per replicate on day 56. These were immersed in formaldehyde before fixation in bouin's solution and paraffin embedding. Paraffin sections at $6 \mu \mathrm{m}$ thickness were made from each sample, stained with hematoxylin and eosin and examined by light microscopy. The lengths of the intestinal villi and the depths of the intestinal crypts were measured with linear scaled graticule.

\section{Gut histopathological Parameters}

From the birds slaughtered at 56 days old, the digestive tracts were carefully excised. The digesta samples from the distal ileum were flushed out. Intestinal samples (about $5 \mathrm{~cm}$ of the jejunum, ileum and caeca) were removed and then transferred into specimen bottles containing $10 \%$ formalin where normal hematoxylin and eosin standard procedures were performed according to the methods of Iji et al. (2001).

\section{Proximate analysis}

The proximate analysis of the experimental diets was carried out according to the methods of AOAC (2000).

\section{Statistical analysis}

Data were analyzed by General Linear Models Procedure using ANOVA of Statistical Analysis System (SAS, 2012). Treatment means were compared using Duncan's multiple range test at $p=0.05$.

\section{Performance indices}

\section{RESULTS}

The performance of the broiler chickens fed diets supplemented with fish oil at the starter and finisher phases are shown in Table 3.

At starter phase, diets had no significant effect on the performance indices measured, however at the finisher phase, they had a significant effect on the final weight and feed conversion ratio. Final weights of birds that received the basal diet $(1736 \mathrm{~g} / \mathrm{b})$ were significantly higher $(\mathrm{P}<0.05)$ than those placed on 5.0\% fish oil $(1556.3 \mathrm{~g} / \mathrm{b})$ supplemented diet. However, the final weight of birds on commercial coccidiostat and $2.5 \%$ fish oil supplemented diets were intermediate between those on the control diet and birds on $5.0 \%$ fish oil diet. Improved feed conversion ratio was observed in birds on 


\section{A. F. Agboola et al.}

the basal diet followed by those on the commercial coccidiostat diet.

\section{Gut morphological indices}

The results of the gut morphological indices of broiler chickens fed diets supplemented with fish oil are shown in Table 4. There were no significant differences observed in the crypt width, villus width, epithelial thickness and villus to crypt depth ratio of birds on the experimental diets. However, crypt depth and villus height of birds fed with $5.0 \%$ fish oil supplemented diet were significantly higher $(\mathrm{P}<0.05)$ than those on other dietary treatments.

Qualitative load of protozoa in the gastrointestinal tract

The results of the protozoa load in the GIT of broiler chickens are shown in Table 5. Birds on the control diet had numerous coccidia while those on commercial coccidiostat, $2.5 \%$ and $5.0 \%$ dietary fish oil had fewer coccidia recorded.

\section{Histopathological readings \\ Photomicrographs of birds fed the basal diet (no supplement: Treatment \\ 1)}

Plates 1, 2 and 3 show the sample sectioning of jejunum, ileum and caeca of birds fed the basal (control) diet respectively. It was observed that in the jejunum, there was necrosis of the enterocytes with oocysts and sporozoites. Numerous developing stages of coccidia in the degenerated enterocytes and loss of villi tips and atrophy were also observed. In the ileum, there was cryptal degeneration. cryptal necrosis, villi atrophy and cellular infiltrate in the mucosa. In the caeca there was degeneration and atrophy of glands and diffuse cellular infiltrates in the mucosa and necrosis of mucous cells.

\section{Photomicrographs of birds fed the basal diet + commercial coccidiostat (Treatment 2)}

Plates 4, 5 and 6 show the sample sectioning of jejunum, ileum and caeca of birds fed the basal diet + commercial coccidiostat respectively. The jejunum was normal with no observable lesion. The ileum showed fusion and atrophy of villi, necrosis of villi enterocytes, cryptal hyperplasia and a few inflammatory cells while the caeca showed necrosis of mucous cells and glandular atrophy.

Photomicrographs of birds fed the basal diet $+\mathbf{2 . 5 \%}$ fish oil (Treatment 3) Plates 7, 8 and 9 show the sample sectioning of jejunum, ileum and caeca of birds fed the basal diet $+2.5 \%$ fish oil respectively. In the jejunum, there was fusion and atrophy of villi, loss of surface enterocytes and mild expansion of lamina propria. The ileum showed thinned villi, cryptal and enterocytic necrosis and cellular debris in lumen. Caeca showed infiltrates of lamina propria and submucosa by inflammatory cells.

\section{Photomicrographs of birds fed the} basal diet $+\mathbf{5 . 0 \%}$ fish oil (Treatment 4 ) Plates 10, 11 and 12 show the sample sectioning of jejunum, ileum and caeca of birds fed the basal diet $+5.0 \%$ fish oil respectively. The jejunum showed normal villi with no observable lesions. The ileum showed necrosis of enterocytes and villi atrophy. Caeca showed normal mucosa with no observable lesions.

\section{DISCUSSION}

\section{Performance}

The results of the present study showed that dietary fish oil supplementation did not have significant effect on the performance of broiler chickens at the starter phase. However, there was a negative effect of the fish oil in the final weight and feed conversion ratio of birds 


\section{Broilers, Fish oil, Growth response, Microbiome, Histology}

at the finisher phase. Crespo and EsteveGarcia (2001) reported no notable effect of 6 and $10 \%$ olive oil supplementation on the final live weight and feed conversion ratio in broilers. Also, Muranmatsu et al. (2005) did not find any effect of soyabean oil supplementation on feed intake in layers. According to Basmacioğlu-Malayoğlu et al. (2010), either enzyme or essential oil, alone or in combination did not improve feed intake and feed conversion ratio of broiler chicks over the 21-d growth period. Similarly, Agboola et al. (2016) reported no significant differences observed in the production performance and egg cholesterol contents when four dietary oils (palm oil, soya bean oil, sesame seed oil and fish oil) supplementation were fed to Isa Brown laying hens. However, diets supplemented with poultry oil, corn oil or fish oil at $45 \mathrm{~g} / \mathrm{kg}$ resulted in higher body weight gain than with oils at $25 \mathrm{~g} / \mathrm{kg}$ or without oils in male Arbor Acres chickens (Yang et al., 2006). Similarly, Amerah et al. (2011), averred an improvement in the body weight gain of broiler chickens when essential oil was added to whole wheat and ground wheat diets. Inconsistencies in the various findings could be attributed to sources and types of dietary oil used, diet composition, feeding regime, species of poultry etc.

\section{Gut morphology}

Intestinal morphology changes with nutritional variations, stress, aging and/or disease and consequently affects the physiology of the intestine, specifically nutrient absorption and metabolism (Kristy et al., 2005). Villus height and crypt depth are direct representations of the intestinal functional condition and may be used as indicators of intestinal health (Kristy et al., 2005). It is assumed that increased villus height is paralleled by enhanced digestive and absorptive functions of the intestine due to larger absorptive surface area and higher expression of brush border enzymes and nutrient transport systems (Pluske et al., 1996). In the present study, higher villus height was recorded in birds that received $5 \%$ fish oil supplemented diet. This is in agreement with the findings of Chowdhury et al. (2018) who reported that cinnamon bark oil diet significantly increased the villi height in duodenum, jejunum or ileum compared with the control in broiler chickens. Crypts act as the villi production factory and deeper crypt is a sign of more active cellular turnover and higher demand for newly formed tissues (Yason et al., 1987). Deeper crypts were observed in birds fed diet supplemented with $5.0 \%$ fish oil although villus height to crypt ratio was similar in all the dietary treatments. However, increased villi height suggests an increased surface area for greater absorption of available nutrients for birds that received $5.0 \%$ fish oil diet. Hajiaghapour and Rezaeipour (2018) reported increased villus width and height in the jejunum and ileum of quail breeders fed dietary ajwain essential oil, probiotic, and mannan-oligosaccharides. Similarly, Pham et al. (2020) asserted a higher villus height and villus height/crypt depth ratio when a blend of encapsulated essential oils and organic acids supplemented diet was fed to broiler chicks co-challenged with Eimeria spp./C. perfringens.

\section{Intestinal protozoa}

The balance of intestinal microbiota is important to promote healthy gut and maximum growth performance of chickens (Kabir, 2009). In this present study, protozoan load counts were 


\section{A. F. Agboola et al.}

significantly reduced in the birds fed diets supplemented with the commercial coccidiostat and dietary fish oil compared with those on the control diet. This result is in consonance with the findings of Allen and Danforth (1998) who reported reduction in lesion scores and parasite scores of $E$. tenella-infected broiler chicks when ethyl esters of eicosapentaenoic and docosahexaenoic acids were added to a broiler starter diet singly or in combination [as bulk purified ethyl ester concentrate from menhaden oil. Danforth et al. (1997) reported ultrastructural degradation of both asexual and sexual parasite stages in development of Eimeria tenella in chickens fed high n-3 fatty acids diets. The ameliorating effects of adding 5\% menhaden oil in a broiler diet resulted in significantly reduced caeca lesions caused by E. tenella (Allen et al., 1997). According to IFOMA (1999), incorporation of omega-3 fatty acids in the diet of chicks challenged with coccidiosis (E. tenella) reduced the adverse effects on growth and reduced gut lesion scores. The results of the present study are consistent with previous findings on the mitigation of coccidiosis using dietary n-3 fatty acids.

\section{Gut histopathology}

Mucosa status and their microscopic structures may be a good indicator of the response of the intestinal tract to active substances present in feeds and in the intestinal contents (Viverros et al., 2011). The present study reveals various histopathological features of the different segments of the gastrointestinal tract (GIT) which include villi atrophy, expansion of lamina propria, necrosis, GALT hyperplasia and cryptal degeneration in birds on the control diet. Frazier and Reece (1990) observed changes in the lamina propria, with infiltrations of lymphoid cells, mesenchymal cells and macrophages and cryptal cysts in the intestine of field and experimental cases of 4- to 6-day-old chicks showing early signs of stunting syndrome. The intestinal lesions characterized by severe villi atrophy, changes in surface epithelium and villi may account for some underlying infections. Histopathologic changes observed in the GIT of birds fed the commercial coccidiostat include fusion and atrophy of villi, necrosis of villi enterocytes, cryptal hyperplasia and a few inflammatory cells in the ileum while the caeca showed necrosis of mucous cells and glandular atrophy and jejunum appeared normal with no observable lesions. This is in consonance with the findings of Hassan et al. (2007) who reported intestinal histopathologic changes in villous atrophy and mild-tomarked distention of crypts of Lieberkuhn of the stunted chicks. The atrophy of the villi which is the eroding away of villi tentacles leaving a flat surface signified poor absorption of nutrients. It is assumed that increased villus height is paralleled by enhanced digestive and absorptive functions of the intestine due to larger absorptive surface area (Pluske et al., 1996). Improved gut health was observed in the histopathological findings of birds placed on $5.0 \%$ fish oil supplemented diet as compared to others. This is similar to the reports of Pham et al. (2020) on the reduction of intestinal $C$. perfringens counts and gut lesion scores at $7 \mathrm{~d}$ post-infection when the challenged birds received a blend of encapsulated essential oils and organic acids as compared with those without the blend supplementation. 


\section{Broilers, Fish oil, Growth response, Microbiome, Histology}

\section{CONCLUSION}

The present study showed that the inclusion of dietary fish oil in the diets of broiler chickens did not significantly improve the performance of broiler chickens. However, reduction in the protozoan load, higher villus height for increased absorptive capacity and normal mucosa cells were recorded in birds fed with fish oil supplemented diets. Overall, there was a slight improvement in the gut integrity of the birds. Therefore, based on this study, lower inclusion level of fish oil is recommended in the diet of broiler chickens for improved performance.

Table (1): Composition of starter diets (g/kg DM) .

\begin{tabular}{|l|c|c|c|c|}
\hline Ingredient & $\begin{array}{c}\text { Basal } \\
\text { diet }\end{array}$ & $\begin{array}{c}\text { Basal diet }+ \\
\text { coccidiostat }\end{array}$ & $\begin{array}{c}\text { Basal diet + } \\
\text { 25g/kg fish oil }\end{array}$ & $\begin{array}{c}\text { Basal diet + 50 } \\
\text { g/kg fish oil }\end{array}$ \\
\hline Maize & 558.00 & 557.40 & 533.00 & 475.00 \\
Soyabean meal & 372.00 & 372.00 & 372.00 & 372.00 \\
Fish meal & 25.00 & 25.00 & 25.00 & 25.00 \\
Wheat offal & 10.00 & 10.00 & 10.00 & 43.00 \\
Dicalcium phosphate & 15.00 & 15.00 & 15.00 & 15.00 \\
*Broiler premix & 2.50 & 2.50 & 2.50 & 2.50 \\
Limestone & 10.00 & 10.00 & 10.00 & 10.00 \\
Methionine & 2.50 & 2.50 & 2.50 & 2.50 \\
Lysine & 2.50 & 2.50 & 2.50 & 2.50 \\
Table salt & 2.50 & 2.50 & 2.50 & 2.50 \\
Fish oil & 0.00 & 0.00 & 25.00 & 50.00 \\
**Coccidiostat & 0.00 & 0.60 & 0.00 & 0.00 \\
Total & $\mathbf{1 0 0 0 . 0 0}$ & $\mathbf{1 0 0 0 . 0 0}$ & $\mathbf{1 0 0 0 . 0 0}$ & $\mathbf{1 0 0 0 . 0 0}$ \\
\hline Calculated nutrients $(\mathbf{g} / \mathbf{k g})$ & & & & \\
\hline Crude protein & 231.74 & 231.68 & 229.24 & 229.05 \\
Energy ME, kcal/kg & 3011 & 3009 & 3174 & 3285 \\
Ether extract & 32.51 & 32.49 & 31.44 & 30.40 \\
Crude Fibre & 39.42 & 39.40 & 38.87 & 40.40 \\
Calcium & 9.69 & 9.69 & 9.69 & 9.72 \\
Total phosphorus & 7.38 & 7.38 & 7.32 & 7.62 \\
Non-phytate P & 3.90 & 3.90 & 3.88 & 3.81 \\
\hline
\end{tabular}

*Composition of premix per kg of diet: vitamin A, 12,500 i.u; vitamin D3, 2,500 i.u; vitamin E, 40mg; vitamin $\mathrm{K} 3,2 \mathrm{mg}$; vitamin $\mathrm{B}_{1}, 3 \mathrm{mg}$; vitamin $\mathrm{B}_{2}, 5,5 \mathrm{mg}$; calcium pantothenate, $11.5 \mathrm{mg}$; vitamin $\mathrm{B} 6,5 \mathrm{mg}$; vitamin $\mathrm{B}_{12}, 0.025 \mathrm{mg}$, choline chloride, 500mg; folic acid, 1mg; biotin, $0.08 \mathrm{mg}$; manganese, $120 \mathrm{mg}$; iron, $100 \mathrm{mg}$; zinc, $80 \mathrm{mg}$; copper, $8.5 \mathrm{mg}$; iodine, $1.5 \mathrm{mg}$; cobalt, $0.3 \mathrm{mg}$; selenium, $0.12 \mathrm{mg}$; anti-oxidant, $120 \mathrm{mg}$. **Coccidiostat contains Amprolium hydrochloridum $200 \mathrm{mg}$ 


\section{A. F. Agboola et al.}

Table (2): Composition of finisher diets ( $\mathrm{g} / \mathrm{kgDM})$.

\begin{tabular}{|l|c|c|c|c|}
\hline Ingredient & $\begin{array}{c}\text { Basal } \\
\text { diet }\end{array}$ & $\begin{array}{c}\text { Basal diet }+ \\
\text { coccidiostat }\end{array}$ & $\begin{array}{c}\text { Basal diet + } \\
\mathbf{2 5 g} \text { fish } \\
\text { oil }\end{array}$ & $\begin{array}{c}\text { Basal diet + } \\
\mathbf{5 0} \text { g/kg fish } \\
\text { oil }\end{array}$ \\
\hline Maize & 610.00 & 600.00 & 540.00 & 450.00 \\
Soyabean meal & 285.00 & 285.00 & 285.00 & 285.00 \\
Fish meal & 25.00 & 25.00 & 25.00 & 25.00 \\
Wheat offal & 45.00 & 54.40 & 90.00 & 155.00 \\
Dicalcium phosphate & 15.00 & 15.00 & 15.00 & 15.00 \\
*Broiler premix & 2.50 & 2.50 & 2.50 & 2.50 \\
Limestone & 10.00 & 10.00 & 10.00 & 10.00 \\
Methionine & 2.50 & 2.50 & 2.50 & 2.50 \\
Lysine & 2.50 & 2.50 & 2.50 & 2.50 \\
Table salt & 2.50 & 2.50 & 2.50 & 2.50 \\
Fish oil & 0.00 & 0.00 & 25.00 & 50.00 \\
**Coccidiostat & 0.00 & 0.60 & 0.00 & 0.00 \\
Total & $\mathbf{1 0 0 0 . 0 0}$ & $\mathbf{1 0 0 0 . 0 0}$ & $\mathbf{1 0 0 0 . 0 0}$ & $\mathbf{1 0 0 0 . 0 0}$ \\
\hline Calculated nutrients (g/kg) & & & & \\
\hline Crude protein & 206.35 & 206.94 & 207.00 & 209.05 \\
Energy ME, kcal/kg & 3020 & 3003 & 3112 & 3174 \\
Ether extract & 39.31 & 39.29 & 38.28 & 37.27 \\
Crude Fibre & 37.45 & 38.02 & 39.73 & 43.28 \\
Calcium & 9.29 & 9.29 & 9.33 & 9.40 \\
Total phosphorus & 7.33 & 7.43 & 7.76 & 8.40 \\
Non-phytate P & 3.76 & 3.76 & 3.66 & 3.67 \\
\hline
\end{tabular}

*Composition of premix per $\mathrm{kg}$ of diet: vitamin A, 12,500 i.u; vitamin D3, 2,500 i.u; vitamin $\mathrm{E}$, 40mg; vitamin $\mathrm{K} 3,2 \mathrm{mg}$; vitamin $\mathrm{B}_{1}, 3 \mathrm{mg}$; vitamin $\mathrm{B}_{2}, 5,5 \mathrm{mg}$; calcium pantothenate, $11.5 \mathrm{mg}$; vitamin $\mathrm{B} 6,5 \mathrm{mg}$; vitamin $\mathrm{B}_{12}, 0.025 \mathrm{mg}$, choline chloride, 500mg; folic acid, $1 \mathrm{mg}$; biotin, $0.08 \mathrm{mg}$; manganese, $120 \mathrm{mg}$; iron, $100 \mathrm{mg}$; zinc, $80 \mathrm{mg}$; copper, $8.5 \mathrm{mg}$; iodine, $1.5 \mathrm{mg}$; cobalt, $0.3 \mathrm{mg}$; selenium, $0.12 \mathrm{mg}$; anti-oxidant, $120 \mathrm{mg}$. **Coccidiostat contains Amprolium hydrochloridum $200 \mathrm{mg}$ 
Table (3): Performance indices of broiler chickens fed fish oil supplemented diets (starter and finisher phases)

\begin{tabular}{|l|c|c|c|c|c|c|}
\hline \multicolumn{1}{|c|}{ Parameter } & $\begin{array}{c}\text { Basal } \\
\text { diet }\end{array}$ & $\begin{array}{c}\text { Basal diet } \\
+ \\
\text { coccidiostat }\end{array}$ & $\begin{array}{c}\text { Basal } \\
\text { diet }+ \\
\mathbf{2 . 5 \%} \\
\text { fish oil }\end{array}$ & $\begin{array}{c}\text { Basal } \\
\text { diet }+ \\
\mathbf{5 . 0 \%} \\
\text { fish oil }\end{array}$ & SEM & $\begin{array}{c}\text { P } \\
\text { value }\end{array}$ \\
\hline Starter phase & & & & & & \\
\hline Initial weight (g/b) & 40.14 & 40.02 & 40.18 & 40.16 & 1.16 & 0.9997 \\
Final weight (g/b) & 789.08 & 764.24 & 803.58 & 796.74 & 21.94 & 0.6167 \\
Weight gain (g/b) & 748.94 & 724.22 & 763.40 & 756.58 & 21.49 & 0.6046 \\
Feed intake(g/b) & 1556.00 & 1576.00 & 1526.00 & 1560.00 & 43.27 & 0.8592 \\
Feed conversion ratio & 2.09 & 2.18 & 2.01 & 2.07 & 0.06 & 0.2668 \\
\hline Finisher phase & & & & & & \\
\hline Initial weight (g/b) & 789.08 & 764.24 & 803.58 & 796.74 & 21.94 & 0.6167 \\
Final weight (g/b) & $1736.00^{\mathrm{a}}$ & $1582.40^{\mathrm{ab}}$ & $1629.00^{\mathrm{ab}}$ & $1556.30^{\mathrm{b}}$ & 88.31 & 0.0509 \\
Weight gain $(\mathrm{g} / \mathrm{b})$ & 946.90 & 818.20 & 825.40 & 759.60 & 77.50 & 0.4057 \\
Feed intake (g/b) & 2802.00 & 2710.00 & 2816.00 & 2716.00 & 78.42 & 0.6837 \\
Feed conversion ratio & $2.99^{\mathrm{b}}$ & $3.36^{\mathrm{ab}}$ & $3.70^{\mathrm{a}}$ & $3.65^{\mathrm{a}}$ & 0.32 & 0.0397 \\
\hline
\end{tabular}

Means in the same row with different superscripts are significantly $(\mathrm{P}<0.05)$ different, SEM: Standard Error of Mean. 
Table (4): Morphological indices of broiler chickens fed fish oil supplemented diets

\begin{tabular}{|c|c|c|c|c|c|c|}
\hline Parameter & Basal diet & $\begin{array}{c}\text { Basal diet } \\
+ \\
\text { coccidiostat }\end{array}$ & $\begin{array}{c}\text { Basal diet }+2.5 \% \\
\text { fish oil }\end{array}$ & $\begin{array}{l}\text { Basal diet }+ \\
5.0 \% \text { fish oil }\end{array}$ & SEM & $P$ value \\
\hline $\begin{array}{l}\text { Crypt depth }(\mu \mathrm{m}) \\
\text { Villus height }(\mu \mathrm{m}) \\
\text { Crypt width }(\mu \mathrm{m}) \\
\text { Villus width }(\mu \mathrm{m}) \\
\text { Epithelial thickness }(\mu \mathrm{m}) \\
\text { Villus height / Crypt depth ratio }\end{array}$ & $\begin{array}{c}144.67^{\mathrm{b}} \\
1410.90^{\mathrm{b}} \\
64.62 \\
141.95 \\
2.58 \\
9.81 \\
\end{array}$ & $\begin{array}{c}149.59^{\mathrm{b}} \\
1403.90^{\mathrm{b}} \\
60.94 \\
146.9 \\
2.92 \\
9.38\end{array}$ & $\begin{array}{c}152.57^{\mathrm{b}} \\
1331.8^{\mathrm{b}} \\
66.80 \\
139.63 \\
3.19 \\
8.72 \\
\end{array}$ & $\begin{array}{c}184.91^{\mathrm{a}} \\
1619.80^{\mathrm{a}} \\
53.07 \\
131.78 \\
2.90 \\
8.77 \\
\end{array}$ & $\begin{array}{c}17.25 \\
106.32 \\
6.56 \\
14.61 \\
0.32 \\
0.57 \\
\end{array}$ & $\begin{array}{c}0.0048 \\
0.029 \\
0.4894 \\
0.9154 \\
0.6175 \\
0.5078\end{array}$ \\
\hline
\end{tabular}


Table (5): Protozoa load in broiler chickens fed fish oil supplemented diets

\begin{tabular}{|l|l|l|l|l|}
\hline Load count & Basal diet & $\begin{array}{l}\text { Basal diet }+ \\
\text { coccidiostat }\end{array}$ & $\begin{array}{l}\text { Basal diet }+ \\
\mathbf{2 . 5 \%} \text { fish oil }\end{array}$ & $\begin{array}{l}\text { Basal diet }+ \\
\mathbf{5 . 0 \%} \text { fish oil }\end{array}$ \\
\hline $\begin{array}{l}\text { Free } \\
\text { Few }\end{array}$ & & $* *$ & $* *$ & $* *$ \\
Numerous & $* * * *$ & & & \\
\hline
\end{tabular}

**fewer coccidia load, $* * * *$ numerous coccidia load

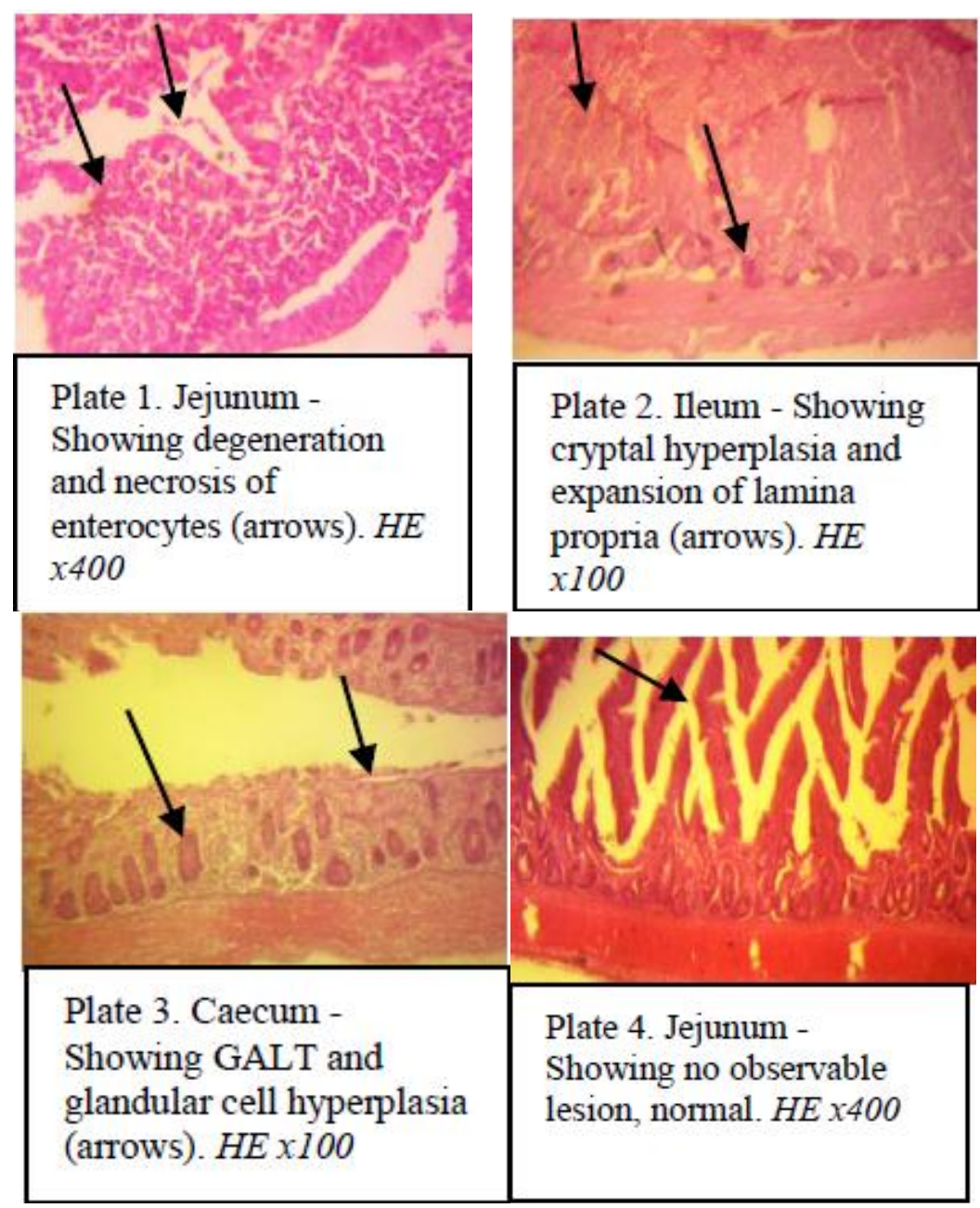


A. F. Agboola et al.

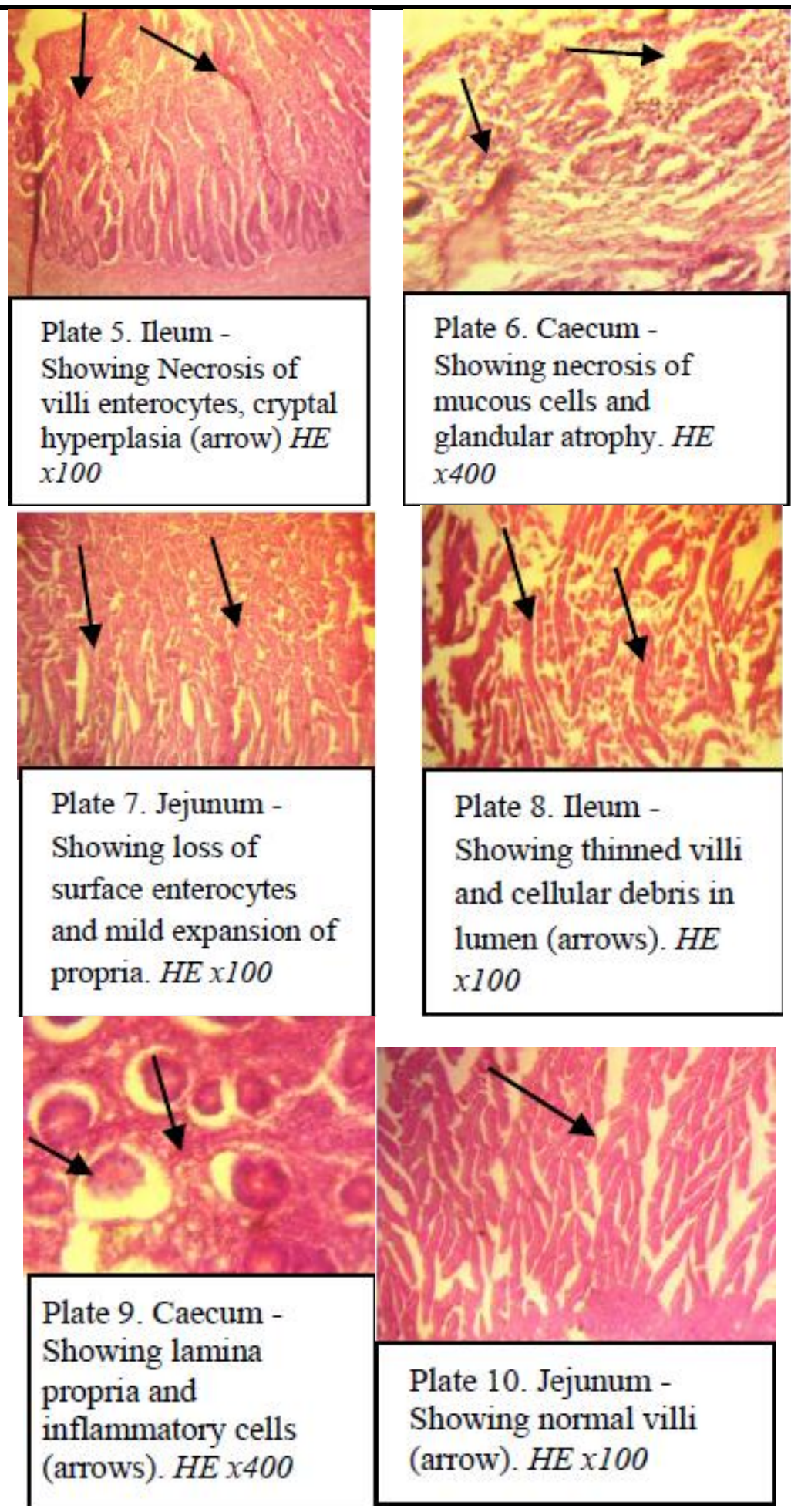




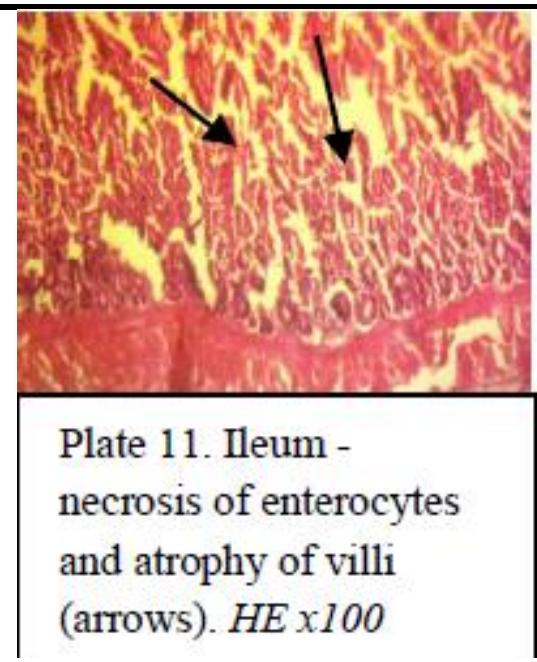

\section{REFERENCES}

Agboola, A. F.; Omidiwura, B. R. O.; Oyeyemi, A.; Iyayi, E. A.; and Adelani, A. 2016. 'Effects of Four Dietary Oils on Cholesterol and Fatty Acid Composition of Egg Yolk in Layers'. World Academy of Science, Engineering and Technology, International Science Index 110, International Journal of Biological, Biomolecular, Agricultural, Food and Biotechnological Engineering, 10(2): 32-39.

Alabi, R. A.; and Osifo, R. A. 2004. Constraints to self-sufficiency in Backyard Poultry Production in Edo State, Nigeria. Proceedings of 9th Annual Conference of Animal Science Association of Nigeria (ASAN), 177180.

Allen, P. C.; Danforth, H. D.; and Levander, O. A. 1996. Diets high in n-3 fatty acids reduce cecal lesion scores in broiler chickens infected with Eimeria tenella. Poultry Science,75: 179-185.

Allen, P. C.; Danforth, H. D.; and Levander, O. A. 1997. Interaction of dietary flaxseed with coccidia infections in chickens. Poultry

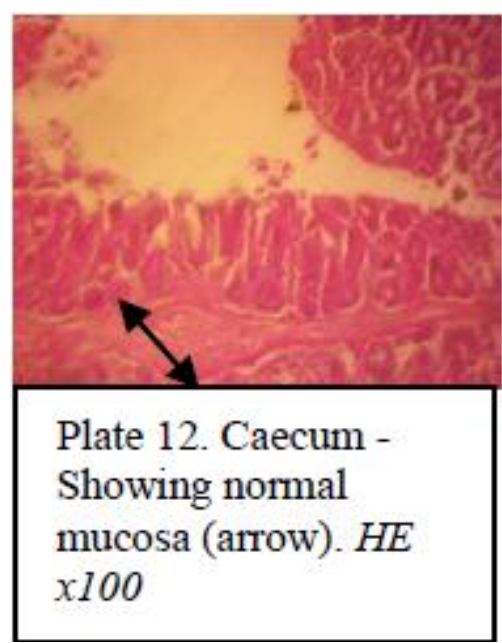

Science, 76(6):822-827. https://doi.org/10.1093/ps/76.6.822.

Allen, P. C.; and Danforth, H. D. 1998. Effects of dietary supplementation with n-3 fatty acid ethyl esters on coccidiosis in chickens. Poultry Science, $\quad$ 77(11): 16311635.https://doi.org/10.1093/ps/77.11. 1631.

Allen, P. C.; Danforth, H.D.; and Augustine, P. C. 1998. Dietary modulation of avian coccidiosis. International Journal Parasitol., 28: 1131-1140.

Amerah, A. M.; Péron, A.; Zaefarian, F.; and Ravindran, V. 2011. Influence of whole wheat inclusion and a blend of essential oils on the performance, nutrient utilization, digestive tract development and ileal microbiota profile of broiler chickens. Br. Poult. Sci., 52(1): 12432.

doi:

10.1080/00071668.2010.548791.

AOAC, 2000. Official methods of analysis. 17th edition, The association of official analytical chemists, Gaithersburg, MD, USA.

Basmacioğlu-Malayoğlu, H.; Baysal, Ş.; Misirlioğlu, Z.; Polat, M.; 


\section{A. F. Agboola et al.}

Yilmaz, H.; and Turan, N. 2010.

Effects of oregano essential oil with or without feed enzymes on growth performance, digestive enzyme, nutrient digestibility, lipid metabolism and immune response of broilers fed on wheat-soybean meal diets. Br. Poult. Sci., 51: 67-80. doi: 10.1080/00071660903573702.

Blake, D. P.; and Tomley F. M. 2014. Securing poultry production from the ever-present Eimeria challenge. Trends $\quad$ Parasitol., 30:1219.

Blake, D. P.; Knox, J.; Dehaeck, B.; Huntington, B.; Rathinam, T.; Ravipati, V.; Ayoade, S.; Gilbert, W.; Adebambo, A. O.; Jatau, I. D.; Raman, M.; Parker, D.; Rushton, J.; and Tomley, F. M. 2020. Re-calculating the cost of coccidiosis in chickens. Vet Res., 51(1):115. doi: 10.1186/s13567-02000837-2.

Chowdhury, S.; Mandal, G. P.; Patra, A. K.; Kumar, P.; Samanta, I.; Pradhan, S.; and Samanta, A. K. 2018. Different essential oils in diets of broiler chickens: 2. Gut microbes and morphology, immune response, and some blood profile and antioxidant enzymes. Animal Feed Science and Technology, 236:39-47. https://doi.org/10.1016/j.anifeedsci.20 17.12.003.

Crespo, N.; and Esteve-Garcia, E. 2001. Dietary fatty acid profile modifies abdominal fat deposition in broiler chickens. Poultry Science, 80:71-78.

Danforth, H.; Allen, P.; and Levander, O. 1997. The effect of high n-3 fatty acid diets on the ultrastructural development of E. tenella. Parasitol Res.,

83:440-444. https://doi.org/10.1007/s00436005027 $\underline{7}$

Frazier, J. A.; and Reece, R. L. 1990. "Infectious stunting syndrome of chickens in Great Britain: intestinal ultrastructural pathology," Avian Pathology, 19(4): 759-777.

Fritsche, K. L.; and Cassity, N. A. 1992. Dietary n-3 fatty acids reduce antibody-dependent cell cytotoxicity and alter eicosanoid release by chicken immune cells. Poultry Science. 71(10): 1646-1657. https://doi.org/10.3382/ps.0711646.

Hajiaghapour, M.; and Rezaeipour, V. 2018. Comparison of two herbal essential oils, probiotic, and mannanoligosaccharides on egg production, hatchability, serum metabolites, intestinal morphology, and microbiota activity of quail breeders. Livestock Science, 210: 93-98.

Hassan, N.; Jahantigh, M.; and Nazifi. S. 2007. Clinical observation, pathology, and serum biochemical changes in infectious stunting syndrome of broiler chickens. Comparative Clinical Pathology, 16(3):161-166.

IFOMA, 1999. International fishmeal and oil manufacturers association. fish oil reduces performance loss due to coccidiosis in broiler chicks. Ifoma fish meal bulletin, College Yard, Lower Dagnall Street, St Albans, Hertfordshire AL3 4PA, UK No. 23, October 1999, 1-4.

Iji, P. A.; Saki, A.; and Tivey, D. R. 2001. Body and intestinal growth of broiler chicks on a commercial starter diet. 1. Intestinal weight and mucosal development. British Poultry Science, 42(4): 505-513.

Kabir, S. M. L. 2009. The role of probiotics in the poultry industry. 
Broilers, Fish oil, Growth response, Microbiome, Histology

International Journal Molecular Science, 10: 3531-3546.

Kristy, N. K.; Kelly, S.; Swanson, K. A.; Tappenden, L. B. S.; and George C. F. J. 2005. Diet and age affect intestinal morphology and large bowel fermentative end-product concentrations in senior and young adult dogs. Journal Nutrition, 135: 1940-1945.

Muramatsu, K.; Stringhini, J. H.; Cafe, M. B.; Jardim Filho, R. de M.; Andrade, L.; and Godoi, F., 2005. Pearl millet and corn based rations supplemented with different levels of soybean oil on performance and egg quality of laying hens. Acta Scientiarum - Animal Sciences, 27 (1): 43-48.

Pham, V. H.; Kan, L.; Huang, J.; Geng, Y.; Zhen, W.; Guo, Y.; Abbas, W.; and Zhong Wang, Z. 2020. Dietary encapsulated essential oils and organic acids mixture improves gut health in broiler chickens challenged with necrotic enteritis. Journal of Animal Science and Biotechnology, 11:1-8.

Pluske, J. R.; Williams I. H.; and Aherne F. X. 1996. Villous height and crypt depth in piglets in response to increases in the intake of cow's milk after weaning. Animal Science, 62:145-158.
SAS, 2012. Statistical Analysis System, User's Guide. Statistical. Version 9.1th ed. SAS. Inst. Inc. Cary. N.C. USA.

Shirley, M. W.; Smith, A. L.; and Tomley, F. M. 2005. The biology of avian Eimeria with an emphasis on their control by vaccination. Advanced Parasitol, 60:285-330. doi: 10.1016/S0065-308X(05)60005.

Viveros, A.; Chamorro, S.; Pizarro, M.; Arija, I.; Centeno, C.; and Brenes, A. 2011. Effects of dietary polyphenol-rich grape products on intestinal microflora and gut morphology in broiler chicks. Poultry Science, 90(3): 566-578.

Yang, X.; Guo. Y.; Wang, Z.; and Nie, W. 2006. Fatty acids and coccidiosis: effects of dietary supplementation with different oils on coccidiosis in chickens, Avian Pathology, 35:(5): 373-378, $\quad$ DOI: 10.1080/03079450600921149.

Yason, C. V.; Summers, B. A.; and Schat, K. A. 1987. Pathogenesis of rotavirus infection in various age groups of chickens and turkeys: pathology. American Journal Veterinary, 48: 927-938.

Yun, C. H.; Lillehoj, H. S.; and Lillehoj E. P. 2000. Intestinal Immune responses to coccidiosis. Dev. Comp. Immunol, 24:303-324. 